\title{
Bone Marrow Cell Injection for Chronic Myocardial Ischemia: The Past and the Future
}

\author{
Jan van Ramshorst • Sander F. Rodrigo • \\ Martin J. Schalij • Saskia L. M. A. Beeres • \\ Jeroen J. Bax • Douwe E. Atsma
}

Received: 11 September 2010 / Accepted: 17 November 2010/Published online: 7 January 2011

(C) The Author(s) 2011. This article is published with open access at Springerlink.com

\begin{abstract}
Intramyocardial bone marrow cell injection is currently being investigated as a new therapeutic option for the treatment of chronic myocardial ischemia. Experimental studies and early phase clinical trials established a favorable safety profile of this approach and suggested that bone marrow cell injection was associated with clinical and functional improvements. Recently, a randomized, doubleblind, placebo-controlled trial demonstrated that intramyocardial bone marrow cell injection was associated with beneficial effects on myocardial perfusion and anginal symptoms. However, the mechanisms by which bone marrow cells may improve myocardial perfusion are only partially understood, and several issues remain to be addressed. This review aims to provide a summary of the current experience with bone marrow cell therapy as a novel treatment option for patients with chronic myocardial ischemia. Therefore, the most frequently used cell types will be reviewed along with the mechanisms through which bone marrow cells may improve myocardial perfusion and function. In addition, possible routes of delivery are compared, and the results of currently available experimental and clinical studies are discussed.
\end{abstract}

Keywords Cell therapy $\cdot$ Myocardial ischemia $\cdot$ Bone marrow cells $\cdot$ Intramyocardial injection

J. van Ramshorst · S. F. Rodrigo · M. J. Schalij ·

S. L. M. A. Beeres $\cdot$ J. J. Bax $\cdot$ D. E. Atsma $(\bowtie)$

Department of Cardiology, Leiden University Medical Centre, P.O. Box 9600, 2300 RC, Leiden, The Netherlands

e-mail: d.e.atsma@lumc.nl

D. E. Atsma

Albinusdreef 2,

2333 ZA, Leiden, The Netherlands

\section{Introduction}

Coronary artery disease is a major cause of mortality and morbidity in the western world. Despite successive revascularization procedures, a large number of patients end up with end-stage coronary artery disease, not amenable for mechanical revascularization. These patients often have stress-inducible myocardial ischemia, resulting in disabling complaints of angina, refractory to medical treatment [1]. Intramyocardial bone marrow cell injection is currently under investigation as a new therapeutic option for these patients. This treatment aims to improve myocardial perfusion and contractile function (and decrease anginal complaints) through administration of bone marrow cells into ischemic myocardium.

Although some large multicenter trials have investigated bone marrow cell therapy in patients with acute myocardial infarction, only small- and medium-sized studies have been conducted in patients with chronic myocardial ischemia. In a recently published randomized trial, we documented clinical and functional improvement after bone marrow cell injection in patients with chronic myocardial ischemia [2]. However, the mechanisms by which bone marrow cells may improve myocardial perfusion are not fully understood. Moreover, questions remain with regard to the optimal cell type, cell dose, and delivery route.

This review will focus on the clinical applicability of bone marrow cell therapy as a new therapeutic option for chronic myocardial ischemia and will describe the most frequently used cell types for treatment of myocardial ischemia, as well as the possible modes of cell delivery. Furthermore, an overview is provided of the experimental and clinical studies that investigated bone marrow cell administration for the treatment of chronic myocardial ischemia. 


\section{Cell Types Used for the Treatment of Myocardial Ischemia}

\section{Hematopoietic Stem Cells}

Hematopoietic stem cells (HSC), commonly identified by CD34, CD45, and/or CD133 surface expression, comprise $<0.01 \%$ of the total bone marrow cell population and $1-3 \%$ of the bone marrow mononuclear cell fraction, with very small amounts of HSC circulating in peripheral blood $(<0.1 \%$ of circulating leukocytes). Hematopoietic stem cells have been used for decades for cell transplantation in hematological diseases because of their ability to differentiate to all types of blood cells. In 2001, the concept was introduced that HSC could transdifferentiate into cardiomyocytes, resulting in substantial de novo myocardium formation after myocardial infarction [3]. Since different animal studies yielded discrepant results [4-8], the ability of bone marrow-derived cells to differentiate into cardiac cell types remains subject of controversy [9]. Nonetheless, in the majority of studies, HSC injection was associated with improvements in cardiac function and attenuation of post-infarct remodeling. Since myocardial engraftment of HSC was transient [6], it has been suggested that these functional improvements may be attributable to paracrine effects. Experimental studies demonstrated that CD34+ cells may exert paracrine effects resulting in stimulation of angiogenesis [10], inhibition of apoptosis [11], recruitment of resident cardiac progenitor cells and changing extracellular matrix composition [12]. Because the CD34+ cell fraction is overlapping with other cell types such as endothelial progenitor cells, it is difficult to determine the exact role of HSC and HSC subpopulations in improving myocardial function.

\section{Endothelial Progenitor Cells}

Originally, endothelial progenitor cells (EPC) were defined by the expression of the hematopoietic stem cell markers CD34, CD45, or CD133 and the co-expression of vascular endothelial growth factor receptor-2 [13]. These cells comprise $0.1 \%$ to $0.4 \%$ of mononuclear cells in the bone marrow [14] but can also be detected in peripheral blood at very low concentrations $(<0.1 \%$ of mononuclear cell fraction) [15]. Characterized by high proliferative capacity, these EPC are considered to be circulating angioblasts, since they have the ability to incorporate into foci of neovascularization, differentiate into endothelial cells, and thus, contribute to angiogenesis [16, 17]. However, in culture-expanded EPC, another CD34-/CD14+ cell population expressing monocyte markers was identified. These "early" EPC have relatively low proliferative capacity and are supposed to stimulate angiogenesis predominantly by secreting pro-angiogenic factors $[18,19]$.
Of note, EPC numbers and function have been shown to be inversely related to risk factors for vascular disease [20] and to be reduced in patients with coronary artery disease [21] Moreover, circulating EPC numbers have been identified as an independent predictor of cardiovascular events in patients with coronary artery disease $[15,22]$. On the other hand, EPC numbers and function may improve after medical treatment, such as statin treatment [23-25] or non-pharmacological interventions [26, 27]. These observations suggest an important role for EPC in vascular homeostasis and thus, emphasize the great potential of EPC for vascular regeneration. Nonetheless, therapeutic usefulness of EPC treatment may be hampered by reduced numbers and angiogenic potential in patients with coronary artery disease.

\section{Mesenchymal Stem Cells}

Mesenchymal stem cells (MSC) are multipotent cells that can differentiate amongst others into osteocytes, chondrocytes, and adipocytes. Although MSC represent only $0.001 \%$ to $0.01 \%$ of the nucleated cells in the bone marrow, they can easily be isolated and efficiently be expanded because of their extensive proliferative capacity. It is uncertain whether MSC are present in peripheral blood under physiological circumstances [28].

In several studies, differentiation of MSC into a cardiomyocyte-like phenotype has been observed after intramyocardial injection $[29,30]$. On the contrary, other studies observed improvements in left ventricular (LV) function in the absence of cardiomyogenic differentiation [31-33]. Therefore, the ability of MSC to differentiate into cardiomyocytes in vivo is still subject of debate, and other mechanisms have been proposed to account for the observed improvements in LV function. In particular, it has been suggested that MSC may promote neoangiogenesis by differentiation in endothelial cells and smooth muscle cells [31, 32] and secretion of pro-angiogenic cytokines [34]. Moreover, MSC have immunomodulatory effects and have the ability to reduce inflammation by inhibiting $\mathrm{T}$ cell proliferation and shifting cytokine balance, and may thus beneficially affect post-infarct LV remodeling [35].

Because of the favorable biologic profile of MSC, combined with their accessibility for harvest and propensity to propagate in culture, MSC are promising candidate for therapeutic use for cardiac purposes. Since MSC possess low immunogenicity, they could be used allogeneically [36] and are theoretically suitable "off the shelf" therapeutic use. However, this may be hindered by induction of an immunological response in the recipient of these allogeneic cells, leading to sensitization and accelerated elimination of the injected cells, as previously suggested [37]. 


\section{Bone Marrow-Derived Mononuclear Cells}

Because studies comparing the capacities of these different cell types are scarce, many investigators have chosen a pragmatic approach by using bone marrow-derived mononuclear cells (BMMC), also referred to as "unfractionated" bone marrow cells. The mononuclear cell fraction comprises a heterogeneous cell population including HSCs, EPCs, and MSCs, but also several rare populations such as side population cells and multipotent adult progenitor cells. The bone marrow provides an easily accessible, renewable, and autologous source of BMMC and no extensive ex vivo manipulation is required, facilitating clinical introduction of this technique. Nonetheless, besides these practical advantages, BMMC may be preferred above selected cell types because of other reasons. For example, in a comparative experimental study, van der Bogt et al. observed that BMMC exhibited a more favorable survival pattern of BMMC as compared to MSC and skeletal myoblasts, resulting in reduced LV remodeling after myocardial infarction [38]. In addition, it has been suggested that other, non-progenitor cells present in BMMC, such as macrophages, may contribute to improvement of cardiac function by accelerating vascularization [39]. Therefore, it may be hypothesized that combinations of bone marrowderived cells rather than selected cellular subfractions are more suitable and effective for cardiac cell therapy, as the interplay between the cell types that also occurs in their natural environment in the bone marrow may be necessary for their optimal efficacy in cardiac repair.

\section{Routes of Cell Delivery}

In patients with chronic myocardial ischemia, direct intramyocardial injection is preferred above intracoronary transfusion and intravenous transfusion, since intramyocardial injection allows delivery of cells in ischemic myocardial territories with an occluded coronary artery. Currently, intramyocardial injection has been described using trans-epicardial injection, trans-endocardial injection, and trans-venous injection.

Trans-epicardial injection is usually performed during open heart surgery. During the procedure, the myocardium is visualized and cell injections can be targeted into infarcted areas or ischemic myocardium. Because of its invasiveness, trans-epicardial injection is not performed as a stand-alone procedure and is usually performed as an adjunct to coronary artery bypass grafting. Therefore, it may be difficult to assess the efficacy of cell injection since conventional revascularization is performed simultaneously.

Trans-endocardial injection is most often performed with the use of an endoventricular catheter guided by a three- dimensional (3D) electromechanical mapping system, allowing direct injection of therapeutic cells into the myocardium. Using this non-fluoroscopic, 3D electromechanical mapping system mapping system, viable, hibernating, and infarcted myocardium can be accurately distinguished [40]. As such, the viability of a myocardial site can be assessed before each injection. After acquiring a stable catheter position perpendicular to the myocardial wall, a needle can be extended from the catheter tip and therapeutic cells can be injected in the myocardium. The ability to assess the viability of a potential injection site before injection is a valuable advantage of transendocardial injection, allowing accurate targeting of therapeutic cells into ischemic myocardium or the infarct border zone [41]. Although the risk of endocardial damage and ventricular perforation are considered as potential disadvantages of this approach, more than 100 patients with chronic myocardial ischemia have been successfully injected using a 3D electromechanical mapping system $[2$, $42-45]$, with only one patient reported to have pericardial effusion [2]. In recently infarcted myocardium, however, trans-endocardial injection may pose a larger risk, although a recent study did not observe periprocedural events during trans-endocardial bone marrow cell injection 10 days after myocardial infarction [46].

A small number of studies have investigated transvenous intramyocardial injection technique, involving injection of therapeutic cells through the coronary veins into the myocardium [47-50]. For this purpose, a catheter system with an extendable needle and an ultrasound tip for guidance is used. Since only right-sided catheterization is necessary and no electromechanical mapping is performed, the trans-venous technique may be advantageous with regard to procedural time and procedural-related cost. On the contrary, the insertion of the catheter to the cardiac venous system may cause irreversible damage to the coronary veins, and incorrect positioning of the needle may result in perforation of the venous wall, leading to pericardial hemorrhage. Therefore, larger studies are warranted to investigate the safety and feasibility of this approach.

The optimal cell dose and delivery route are still under investigation. For direct intramyocardial injection, it has been demonstrated that a larger cell dose results in retention of a larger number of cells [51]. Nonetheless, delivery of large amounts of cells may theoretically not always be safe and feasible, although no complications have been observed after intramyocardial delivery. Therefore, optimal cell dose for direct intramyocardial injection, transendocardial injection, and trans-venous intramyocardial injection remains to be determined.

Cell engraftment is not only influenced by the route of delivery, but is also dependent of cell type and myocardial 
substrate. In animal studies, direct intramyocardial injection was associated with engraftment rates ranging from $25 \%$ after $48 \mathrm{~h}$ to $0.3-3.5 \%$ at 6 weeks [51-54]. Transendocardial intramyocardial injection resulted in retention of $11.3 \pm 3 \%$ of the injected cells $1 \mathrm{~h}$ after injection of peripheral blood-derived mononuclear cells in a porcine model of myocardial infarction [55]. In another experimental study, engraftment of $5.8 \pm 1.1 \%$ of the injected cells was demonstrated 10 days after trans-endocardial injection of reporter gene transfected MSC in recently infarcted pig myocardium. Limited data are currently available on cell retention after trans-venous intramyocardial injection, although an initial study demonstrated effective injection and cell engraftment in porcine myocardium after injection of MSC [50].

Since all experimental studies investigating cell fate have been performed using models of myocardial infarction, no data are available about cell engraftment in chronic ischemic myocardium. Until now, most investigators have chosen the trans-endocardial delivery route for the treatment of myocardial ischemia because of its limited invasiveness and favorable safety profile. Nonetheless, additional research is warranted to further explore the fate of the injected cells in chronic ischemic myocardium in relation to the different routes of delivery. Promising strategies to improve cell retention and engraftment are under investigation and may be of crucial importance to improve the functional benefits of stem cell therapy [56].

\section{Experimental Studies}

The majority of experimental studies investigating the effects of cell therapy have been performed in animal models of acute myocardial infarction. Only a minority of studies has been conducted using animal models of chronic myocardial ischemia, such as ameroid constrictor placement in the left anterior descending or circumflex coronary artery. Similar to studies in animal models of acute myocardial infarction models, comparison of different studies is difficult, since differences exist in cell isolation methods, cell dose, timing of delivery, and the characteristics of the animal model. Nonetheless, the results of these studies lead to the concept that bone marrow cell injection in ischemic myocardium may improve myocardial perfusion and function by stimulating angiogenesis, through differentiation into endothelial cells and smooth muscle cells, and secretion of pro-angiogenic cytokines (Fig. 1).

For example, the study of Kawamoto et al. reported macroscopic collateral formation and increased capillary density after intramyocardial cell injection in a swine model of myocardial ischemia [57]. In this study, adhesive $\mathrm{CD} 31+$ cells isolated from peripheral blood were injected in ischemic myocardium using a 3D electromechanical mapping system, resulting in enhanced neovascularization that was accompanied by improvements in LV function. In line with these results, Silva et al. described increased capillary density and improved LV function after MSC injection using a canine ischemia model [31]. In addition, injected MSC were found to colocalize with endothelial cells and smooth muscle cells but not with cardiomyocytes, suggesting differentiation of MSC into these in vascular cell types.

In contrast, Fuchs et al. observed improved myocardial perfusion and enhanced contractility in the absence of microscopic or macroscopic collateral formation [58]. In this study, freshly aspirated, unselected bone marrow cells were injected into ischemic myocardium of pigs using a $3 \mathrm{D}$ electromechanical mapping system. Of note, this study demonstrated that the injected bone marrow cells secreted angiogenic factors, which induced in vitro endothelial cell proliferation, suggesting that the observed improvements were mainly the result of paracrine function of the injected cells, possibly leading to changes in vascular diameters or decreased resistance to collateral flow. Importantly, since freshly aspirated, non-enriched bone marrow was injected in this study, the absence of collateral formation may be attributable to lower dose of progenitor cells as compared to studies using bone marrow mononuclear cells or enriched cell populations. Moreover, red blood cell contamination may have reduced progenitor cell function [59].

In a study focusing on the functional results of bone marrow cell injection, Schneider et al. compared intramyocardial injection of BMMC and MSC in a porcine model of chronic myocardial ischemia [60]. In all celltreated animals, improved LV function, reduced fibrosis, and increased vascular density were observed, with none of both cell types being superior. In addition, using strain rate imaging, a favorable effect on diastolic function was observed, as evidenced by improved parameters of filling pressure and myocardial relaxation.

Importantly, none of the animal studies did pose any concerns with regard to the safety of intramyocardial bone marrow cell injection for chronic myocardial ischemia. Of note, no excessive necrosis was observed at the sites of intramyocardial injection $[57,58]$. Furthermore, in a porcine model of chronic myocardial ischemia, Krause et al. demonstrated that 3D electromechanical mappingguided injection of both bone marrow-derived mononuclear cells and MSC into ischemic myocardium did not increase fragmentation and duration of endocardial electrograms [61]. These findings suggest that injection of either bone marrow cells or MSC is not likely to create a substrate for arrhythmias and confirms observations from early clinical studies [62]. 
Fig. 1 Potential mechanisms by which bone marrow cells may improve myocardial perfusion and anginal symptoms

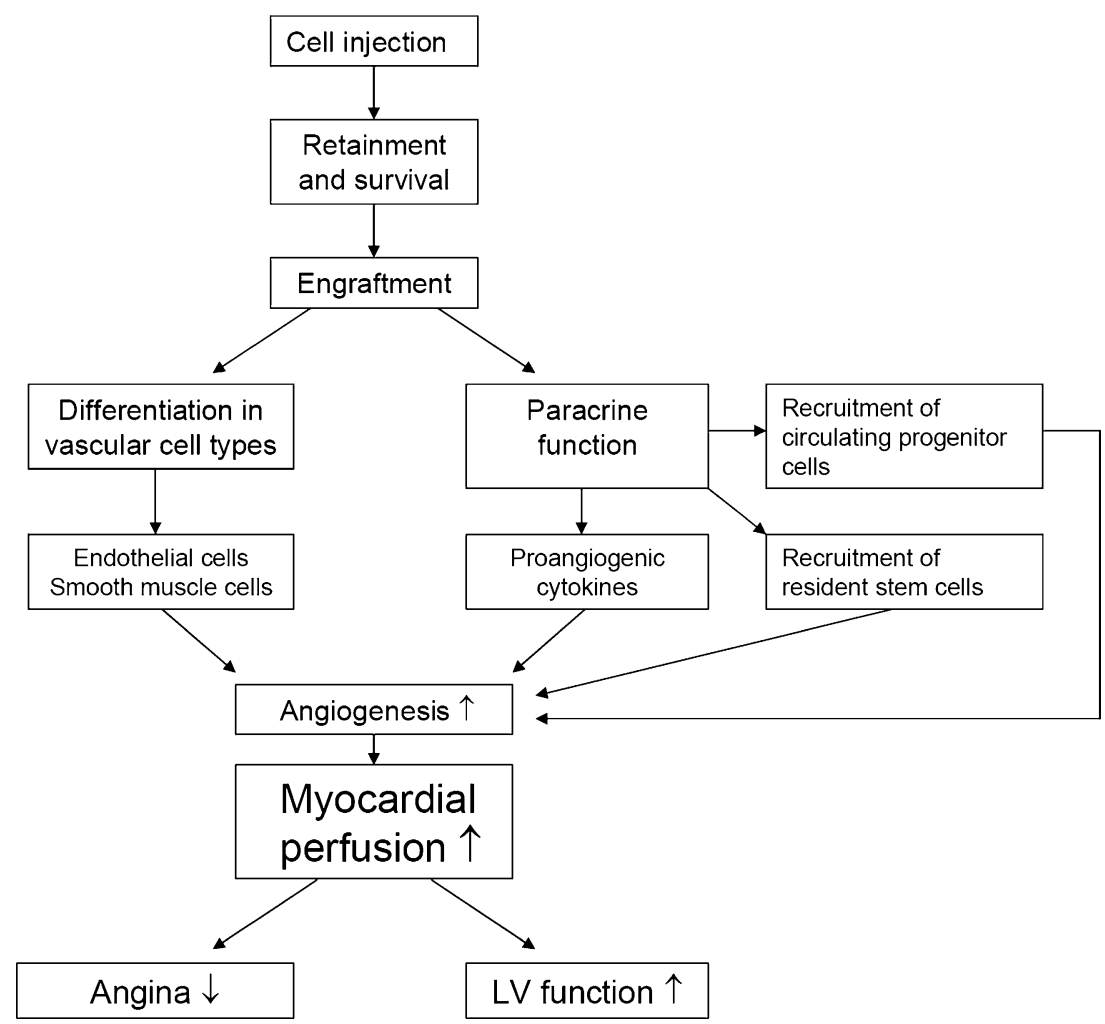

\section{Clinical Studies in Patients with Chronic Myocardial Ischemia}

Supported by encouraging preclinical data and an unmet clinical need, several clinical studies were initiated to investigate intramyocardial bone marrow cell injection as a novel therapeutic option for the treatment of chronic myocardial ischemia. In these studies, patients with refractory angina ineligible for conventional revascularization were treated with trans-endocardial bone marrow cell injection, performed during cardiac catheterization with the use of electromechanical mapping. In Table 1, a summary of these studies is provided. Four studies included patients with angina [42, 43, 63, 64], whereas one study included patients with heart failure [44]. The combined experience of these studies indicated that bone marrow cell injection is a safe and feasible treatment in patients with chronic myocardial ischemia. However, one patient in the study of Perin et al. died suddenly at 14 weeks follow-up. Although sudden cardiac death is a relatively a common complication of ischemic heart failure, a cell-related cause of this event could not be ruled out. Of note, two studies demonstrated that intramyocardial bone marrow cell injection was not associated with progression of atherosclerosis [65] and did not alter the electrophysiological properties of the injected myocardium [62].

Importantly, most of these initial clinical studies reported improvements in myocardial perfusion, LV function and anginal complaints after bone marrow cell injection. Since only preliminary conclusions could be drawn from these nonrandomized studies, several randomized trials were initiated to assess the efficacy of intramyocardial bone marrow cell injection.

In a small-sized randomized trial, Losordo et al. documented the feasibility and safety of intramyocardial injection of granulocyte colony-stimulating factor (G-CSF)mobilized CD34+ stem cells [66]. No significant effect on angina frequency, exercise time, or Canadian Cardiovascular Society (CCS) score was observed, which may have been due to underpowering for these outcomes. In the PROTECT-CAD trial, Tse et al. evaluated the effect of intramyocardial bone marrow cell injection on myocardial perfusion, LV function and clinical parameters in 28 patients with myocardial ischemia [45]. Patients were randomized in a 1:1:1 ratio to receive low dose bone marrow cells $(n=9)$, high dose bone marrow cells $(n=10)$, or placebo solution $(n=9)$. Diabetes and previous percutaneous coronary intervention were more frequent in the placebo group than in the bone marrow cell groups, suggesting that baseline risks were not completely balanced between the groups. Although bone marrow cell injection was associated with a modest increase in exercise capacity and LV ejection fraction, no significant treatment effect on CCS class was observed, indicating no effect of bone marrow cell injection on anginal complaints. Moreover, the changes in myocardial perfusion did not differ significantly 


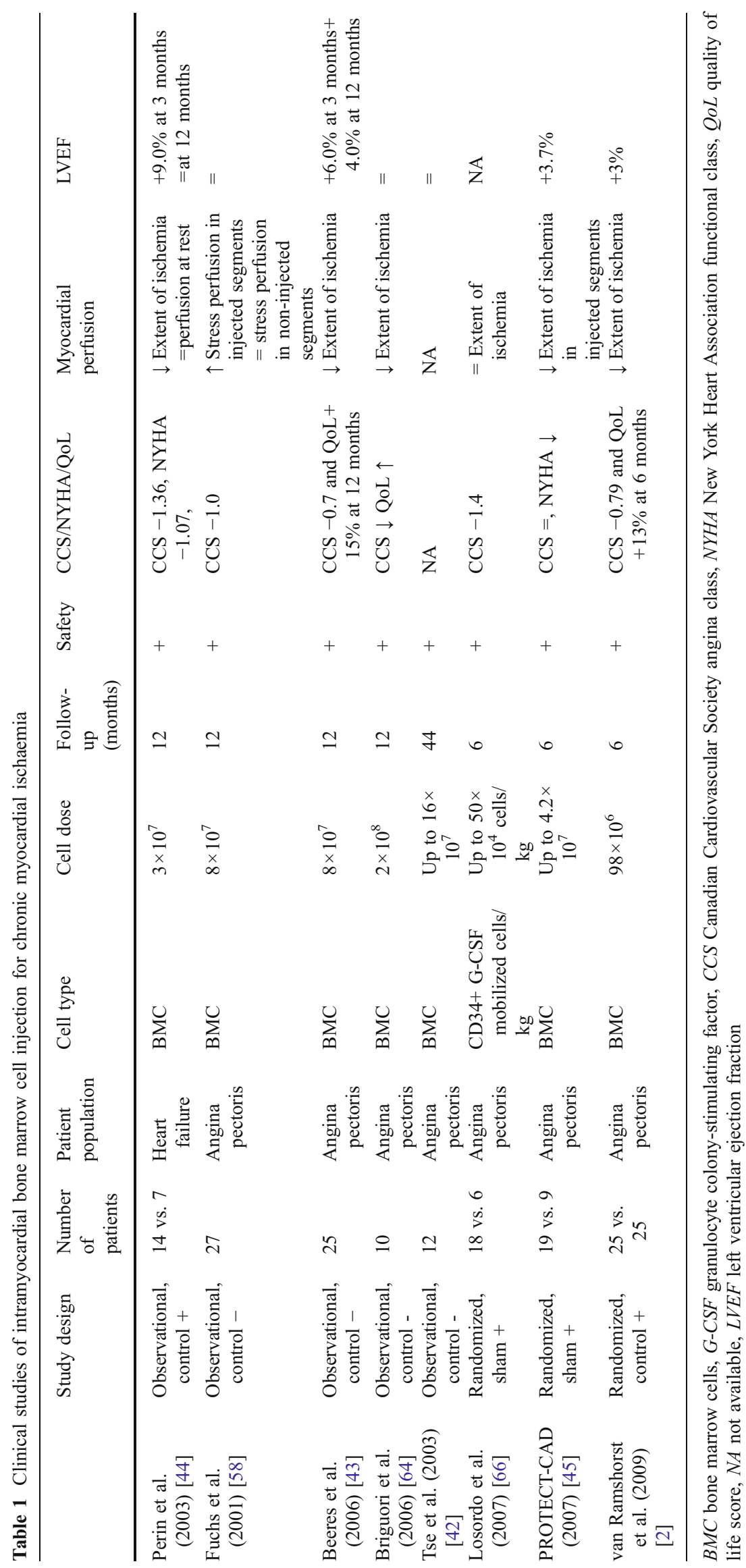


between the (pooled) cell group and the placebo group. Only when post hoc analysis was performed, a significant improvement in myocardial perfusion was observed in bone marrow cell-injected myocardial regions.

In a recently published randomized, double-blind, placebo-controlled trial from our group, 50 patients were randomly assigned to intramyocardial injection of either BMMC or placebo solution [2]. In this study, bone marrow cell injection was associated with a significant improvement in myocardial perfusion, as evidenced by a decrease in ischemic myocardial segments from $3.9 \pm 1.8$ at baseline to $1.5 \pm 1.5$ at 3 months follow-up (treatment effect -2.4 , $95 \%$ CI $-2.9,-1.9$ vs. $-0.8,95 \%$ CI $-1.2,-0.3, P<0.001)$. Single-photon emission computed tomography images from a representative patient from this study are shown in Fig. 2. Furthermore, magnetic resonance imaging revealed a modest but significant improvement in LV ejection fraction. Moreover, these improvements in myocardial perfusion and function were accompanied by a significant improvement in CCS class and an increase in quality of life. Thus, in this study, more pronounced improvements in myocardial perfusion and anginal complaints were observed after bone marrow cell injection as compared to the PROTECT-CAD study. Since a significantly larger amount of cells was injected in this study $\left(98 \pm 7 \times 10^{6}\right.$ as compared with $42 \pm 28 \times 10^{6}$ in the PROTECT-CAD study), it may be hypothesized that these differences are related to a dose-response relationship, as has been suggested in a recent trial in patients with acute
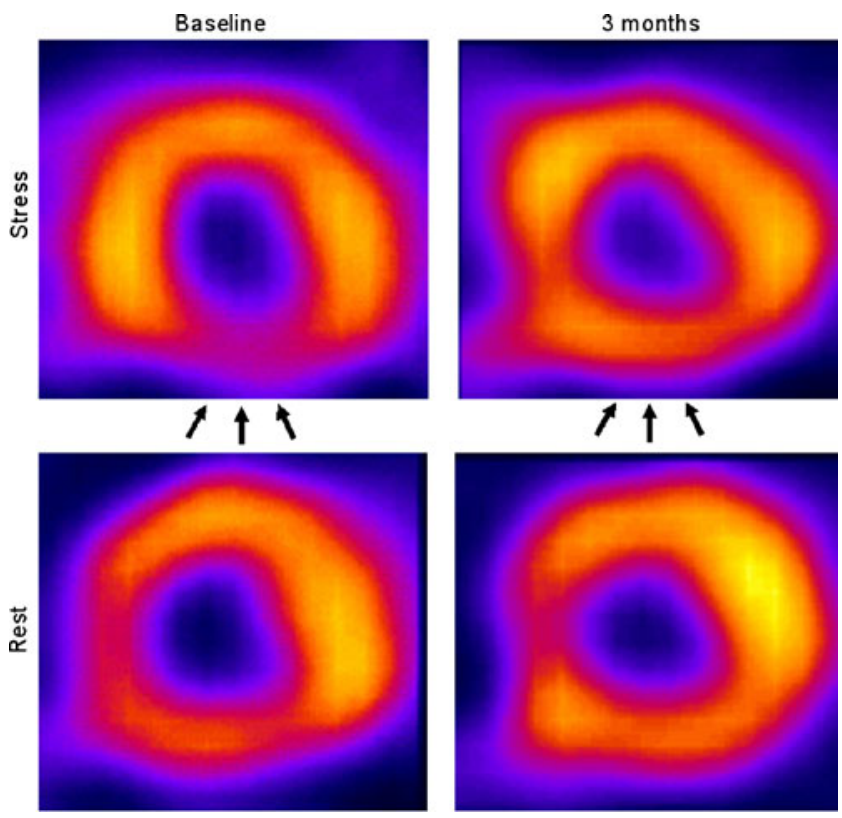

Fig. 2 SPECT images (horizontal short-axis projections) from a representative patient from the study of van Ramshorst et al. $99 \mathrm{mTc}-$ Tetrofosmin SPECT shows stress-induced ischemia at baseline in the inferior wall (arrowheads). At 3 months follow-up, the ischemia in the inferior wall has resolved myocardial infarction [67]. Furthermore, group size was substantially larger in this study as compared with the PROTECT-CAD study and baseline characteristics were well balanced between the groups, which may potentially explain the observed differences.

Preliminary results of a large, multicenter randomized trial document a beneficial effect of intramyocardial injection of G-CSF-mobilized CD34+ cells on exercise time and anginal complaints [68]. However, the final results of this trial, including the effects on myocardial perfusion and anginal complaints, remain to be presented.

\section{Summary and Potential Directions for Future Research}

Intramyocardial bone marrow cell injection has emerged as a promising new treatment strategy for the treatment of patients with chronic myocardial ischemia. Nonrandomized clinical studies indicated the safety and feasibility of this approach, and suggested a beneficial effect on clinical and functional parameters. Until now, one medium-sized randomized trial has confirmed these findings by demonstrating significant improvement in myocardial perfusion and anginal complaints as compared to placebo treatment. In addition, preliminary results from a large multicenter study investigating injection of G-CSF-mobilized CD34+ stem cells support the concept that bone marrow cell injection is an effective treatment for patients with refractory angina without option for conventional revascularization.

In the near future, the effectiveness of bone marrow cell injection should be further explored. For example, future studies will have to investigate whether the observed improvements are sustained over longer periods of followup. In addition, clinical trials such as the ongoing FOCUS trial [69] will point out whether effective treatment of myocardial ischemia by intramyocardial bone marrow cell injection can be extended to patients with LV dysfunction. Furthermore, predictors of response may be identified, since these may provide directions for future experimental research and contribute to patient selection. Finally, future studies will have to assess whether the observed improvements in anginal complaints and myocardial perfusion result in improved survival and/or a reduced number of hospitalizations, because such data are crucial to determine the cost-effectiveness of this novel treatment modality in its current form.

Further innovations which may possibly enhance the efficacy of cell therapy are under investigation. Besides identification of promising cell types [70], strategies have been developed to augment cell engraftment and function $[56,71,72]$, such as pharmacologic stimulation $[73,74]$ or ischemic preconditioning [75]. Furthermore, the combination of gene therapy and cell therapy holds great potential. 
Transduction of genes into stem cells may improve survival, retention, and angiogenic function. On the other hand, stem cells may be used as vectors for local drug delivery. Finally, the use of biomaterials is a promising technique to improve cell retention and survival, which may contribute to the optimization of delivery techniques $[76,77]$. It is hoped that these innovations will result in effective cell-based treatment strategies for a variety of diseases, extending the spectrum of therapeutic options for patients who have exhausted conventional therapies.

Disclosures Jeroen J. Bax has research grants from Biotronik, BMS Medical Imaging, Boston Scientific, Edwards Lifesciences, GE Healthcare, Medtronic, and St. Jude Medical. Martin J. Schalij has research grants from Biotronik, Boston Scientific, and Medtronic.

Open Access This article is distributed under the terms of the Creative Commons Attribution Noncommercial License which permits any noncommercial use, distribution, and reproduction in any medium, provided the original author(s) and source are credited.

\section{References}

1. Yang, E. H., Barsness, G. W., Gersh, B. J., Chandrasekaran, K., \& Lerman, A. (2004). Current and future treatment strategies for refractory angina. Mayo Clinic Proceedings, 79, 1284-1292.

2. van Ramshorst, J., Bax, J. J., Beeres, S. L., Dibbets-Schneider, P., Roes, S. D., Stokkel, M. P., et al. (2009). Intramyocardial bone marrow cell injection for chronic myocardial ischemia: a randomized controlled trial. Journal of American Medical Association, 301, 1997-2004.

3. Orlic, D., Kajstura, J., Chimenti, S., Jakoniuk, I., Anderson, S. M., $\mathrm{Li}, \mathrm{B}$., et al. (2001). Bone marrow cells regenerate infarcted myocardium. Nature, 410, 701-705.

4. Balsam, L. B., Wagers, A. J., Christensen, J. L., Kofidis, T., Weissman, I. L., \& Robbins, R. C. (2004). Haematopoietic stem cells adopt mature haematopoietic fates in ischaemic myocardium. Nature, 428, 668-673.

5. Murry, C. E., Soonpaa, M. H., Reinecke, H., Nakajima, H., Nakajima, H. O., Rubart, M., et al. (2004). Haematopoietic stem cells do not transdifferentiate into cardiac myocytes in myocardial infarcts. Nature, 428, 664-668.

6. Nygren, J. M., Jovinge, S., Breitbach, M., Sawen, P., Roll, W., Hescheler, J., et al. (2004). Bone marrow-derived hematopoietic cells generate cardiomyocytes at a low frequency through cell fusion, but not transdifferentiation. Natural Medicines, 10, 494501.

7. Yeh, E. T., Zhang, S., Wu, H. D., Korbling, M., Willerson, J. T., \& Estrov, Z. (2003). Transdifferentiation of human peripheral blood CD34+-enriched cell population into cardiomyocytes, endothelial cells, and smooth muscle cells in vivo. Circulation, 108, 20702073.

8. Zhang, S., Wang, D., Estrov, Z., Raj, S., Willerson, J. T., \& Yeh, E. T. (2004). Both cell fusion and transdifferentiation account for the transformation of human peripheral blood CD34-positive cells into cardiomyocytes in vivo. Circulation, 110, 3803-3807.

9. Menasche, P. (2006). You can't judge a book by its cover. Circulation, 113, 1275-1277.
10. Yoshioka, T., Ageyama, N., Shibata, H., Yasu, T., Misawa, Y., Takeuchi, K., et al. (2005). Repair of infarcted myocardium mediated by transplanted bone marrow-derived CD34+ stem cells in a nonhuman primate model. Stem Cells, 23, 355-364.

11. Kocher, A. A., Schuster, M. D., Szabolcs, M. J., Takuma, S., Burkhoff, D., Wang, J., et al. (2001). Neovascularization of ischemic myocardium by human bone-marrow-derived angioblasts prevents cardiomyocyte apoptosis, reduces remodeling and improves cardiac function. Natural Medicines, 7, 430-436.

12. Yoon, C. H., Hur, J., Park, K. W., Kim, J. H., Lee, C. S., Oh, I. Y., et al. (2005). Synergistic neovascularization by mixed transplantation of early endothelial progenitor cells and late outgrowth endothelial cells: the role of angiogenic cytokines and matrix metalloproteinases. Circulation, 112, 1618-1627.

13. Asahara, T., \& Kawamoto, A. (2004). Endothelial progenitor cells for postnatal vasculogenesis. American Journal of Physiology. Cell Physiology, 287, C572-C579.

14. Schachinger, V., Erbs, S., Elsasser, A., Haberbosch, W., Hambrecht, R., Holschermann, H., et al. (2006). Intracoronary bone marrowderived progenitor cells in acute myocardial infarction. The New England Journal of Medicine, 355, 1210-1221.

15. Schmidt-Lucke, C., Rossig, L., Fichtlscherer, S., Vasa, M., Britten, M., Kamper, U., et al. (2005). Reduced number of circulating endothelial progenitor cells predicts future cardiovascular events: proof of concept for the clinical importance of endogenous vascular repair. Circulation, 111, 2981-2987.

16. Shantsila, E., Watson, T., Tse, H. F., \& Lip, G. Y. (2008). New insights on endothelial progenitor cell subpopulations and their angiogenic properties. Journal of the American College of Cardiology, 51, 669-671.

17. Friedrich, E. B., Walenta, K., Scharlau, J., Nickenig, G., \& Werner, N. (2006). CD34-/CD133+/VEGFR-2+ endothelial progenitor cell subpopulation with potent vasoregenerative capacities. Circulation Research, 98, e20-e25.

18. Rehman, J., Li, J., Orschell, C. M., \& March, K. L. (2003). Peripheral blood "endothelial progenitor cells" are derived from monocyte/macrophages and secrete angiogenic growth factors. Circulation, 107, 1164-1169.

19. Sieveking, D. P., Buckle, A., Celermajer, D. S., \& Ng, M. K. (2008). Strikingly different angiogenic properties of endothelial progenitor cell subpopulations: insights from a novel human angiogenesis assay. Journal of the American College of Cardiology, 51, 660-668.

20. Hill, J. M., Zalos, G., Halcox, J. P., Schenke, W. H., Waclawiw, M. A., Quyyumi, A. A., et al. (2003). Circulating endothelial progenitor cells, vascular function, and cardiovascular risk. The New England Journal of Medicine, 348, 593-600.

21. Vasa, M., Fichtlscherer, S., Aicher, A., Adler, K., Urbich, C., Martin, H., et al. (2001). Number and migratory activity of circulating endothelial progenitor cells inversely correlate with risk factors for coronary artery disease. Circulation Research, 89, E1-E7.

22. Werner, N., Kosiol, S., Schiegl, T., Ahlers, P., Walenta, K., Link, A., et al. (2005). Circulating endothelial progenitor cells and cardiovascular outcomes. The New England Journal of Medicine, 353, 999-1007.

23. Dimmeler, S., Aicher, A., Vasa, M., Mildner-Rihm, C., Adler, K., Tiemann, M., et al. (2001). HMG-CoA reductase inhibitors (statins) increase endothelial progenitor cells via the PI 3-kinase/ Akt pathway. Journal of Clinical Investigation, 108, 391-397.

24. Vasa, M., Fichtlscherer, S., Adler, K., Aicher, A., Martin, H., Zeiher, A. M., et al. (2001). Increase in circulating endothelial progenitor cells by statin therapy in patients with stable coronary artery disease. Circulation, 103, 2885-2890.

25. Walter, D. H., Rittig, K., Bahlmann, F. H., Kirchmair, R., Silver, M., Murayama, T., et al. (2002). Statin therapy accelerates reendothelialization: a novel effect involving mobilization and 
incorporation of bone marrow-derived endothelial progenitor cells. Circulation, 105, 3017-3024.

26. Muller-Ehmsen, J., Braun, D., Schneider, T., Pfister, R., Worm, N., Wielckens, K., et al. (2008). Decreased number of circulating progenitor cells in obesity: beneficial effects of weight reduction. European Heart Journal, 29, 1560-1568.

27. Croce, G., Passacquale, G., Necozione, S., Ferri, C., \& Desideri, G. (2006). Nonpharmacological treatment of hypercholesterolemia increases circulating endothelial progenitor cell population in adults. Arteriosclerosis, Thrombosis, and Vascular Biology, 26, e38-e39.

28. Tocci, A., \& Forte, L. (2003). Mesenchymal stem cell: use and perspectives. The Hematology Journal, 4, 92-96.

29. Toma, C., Pittenger, M. F., Cahill, K. S., Byrne, B. J., \& Kessler, P. D. (2002). Human mesenchymal stem cells differentiate to a cardiomyocyte phenotype in the adult murine heart. Circulation, 105, 93-98.

30. Tomita, S., Li, R. K., Weisel, R. D., Mickle, D. A., Kim, E. J., Sakai, T., et al. (1999). Autologous transplantation of bone marrow cells improves damaged heart function. Circulation, 100, II247-II256.

31. Silva, G. V., Litovsky, S., Assad, J. A., Sousa, A. L., Martin, B. J., Vela, D., et al. (2005). Mesenchymal stem cells differentiate into an endothelial phenotype, enhance vascular density, and improve heart function in a canine chronic ischemia model. Circulation, $111,150-156$

32. Dai, W., Hale, S. L., Martin, B. J., Kuang, J. Q., Dow, J. S., Wold, L. E., et al. (2005). Allogeneic mesenchymal stem cell transplantation in postinfarcted rat myocardium: short- and long-term effects. Circulation, 112, 214-223.

33. Grauss, R. W., Winter, E. M., van TJ, P., DA, S. R. V., Hogers, B., Van der Geest, R. J., et al. (2007). Mesenchymal stem cells from ischemic heart disease patients improve left ventricular function after acute myocardial infarction. American Journal of Physiology. Heart and Circulatory Physiology, 293, H2438-H2447.

34. Kinnaird, T., Stabile, E., Burnett, M. S., Lee, C. W., Barr, S., Fuchs, S., et al. (2004). Marrow-derived stromal cells express genes encoding a broad spectrum of arteriogenic cytokines and promote in vitro and in vivo arteriogenesis through paracrine mechanisms. Circulation Research, 94, 678-685.

35. Le, B. K., \& Ringden, O. (2007). Immunomodulation by mesenchymal stem cells and clinical experience. Journal of Internal Medicine, 262, 509-525.

36. Liechty, K. W., MacKenzie, T. C., Shaaban, A. F., Radu, A., Moseley, A. M., Deans, R., et al. (2000). Human mesenchymal stem cells engraft and demonstrate site-specific differentiation after in utero transplantation in sheep. Natural Medicines, 6, 1282-1286.

37. Nauta, A. J., Westerhuis, G., Kruisselbrink, A. B., Lurvink, E. G., Willemze, R., \& Fibbe, W. E. (2006). Donor derived mesenchymal stem cells are immunogenic in an allogeneic host and stimulate donor graft rejection in a nonmyeloablative setting. Blood, 108, 2114-2121.

38. van der Bogt, K. E., Sheikh, A. Y., Schrepfer, S., Hoyt, G., Cao, F., Ransohoff, K. J., et al. (2008). Comparison of different adult stem cell types for treatment of myocardial ischemia. Circulation, $118, \mathrm{~S} 121-\mathrm{S} 129$.

39. Leor, J., Rozen, L., Zuloff-Shani, A., Feinberg, M. S., Amsalem, Y., Barbash, I. M., et al. (2006). Ex vivo activated human macrophages improve healing, remodeling, and function of the infarcted heart. Circulation, 114, I94-I100.

40. Kornowski, R., Hong, M. K., \& Gepstein, L. (1998). Preliminary animal and clinical experiences using an electromechanical mapping procedure to distinguish infarcted from healthy myocardium. Circulation, 98, 1116-1124.

41. Beeres, S. L., Bax, J. J., Dibbets-Schneider, P., Stokkel, M. P., Fibbe, W. E., van der Wall, E. E., et al. (2007). Intramyocardial injection of autologous bone marrow mononuclear cells in patients with chronic myocardial infarction and severe left ventricular dysfunction. The American Journal of Cardiology, 100, 1094-1098.

42. Tse, H. F., Kwong, Y. L., Chan, J. K., Lo, G., Ho, C. L., \& Lau, C. P. (2003). Angiogenesis in ischaemic myocardium by intramyocardial autologous bone marrow mononuclear cell implantation. Lancet, $361,47-49$.

43. Beeres, S. L., Bax, J. J., Kaandorp, T. A., Zeppenfeld, K., Lamb, H. J., Dibbets-Schneider, P., et al. (2006). Usefulness of intramyocardial injection of autologous bone marrow-derived mononuclear cells in patients with severe angina pectoris and stress-induced myocardial ischemia. The American Journal of Cardiology, 97, 1326-1331.

44. Perin, E. C., Dohmann, H. F., Borojevic, R., Silva, S. A., Sousa, A. L., Mesquita, C. T., et al. (2003). Transendocardial, autologous bone marrow cell transplantation for severe, chronic ischemic heart failure. Circulation, 107, 2294-2302.

45. Tse, H. F., Thambar, S., Kwong, Y. L., Rowlings, P., Bellamy, G., McCrohon, J., et al. (2007). Prospective randomized trial of direct endomyocardial implantation of bone marrow cells for treatment of severe coronary artery diseases (PROTECT-CAD trial). European Heart Journal, 28, 2998-3005.

46. Krause, K., Jaquet, K., Schneider, C., Haupt, S., Lioznov, M. V., Otte, K. M., et al. (2009). Percutaneous intramyocardial stem cell injection in patients with acute myocardial infarction: first-in-man study. Heart, 95, 1145-1152.

47. Brasselet, C., Morichetti, M. C., Messas, E., Carrion, C., Bissery, A., Bruneval, P., et al. (2005). Skeletal myoblast transplantation through a catheter-based coronary sinus approach: an effective means of improving function of infarcted myocardium. European Heart Journal, 26, 1551-1556.

48. Siminiak, T., Fiszer, D., Jerzykowska, O., Grygielska, B., Rozwadowska, N., Kalmucki, P., et al. (2005). Percutaneous trans-coronary-venous transplantation of autologous skeletal myoblasts in the treatment of post-infarction myocardial contractility impairment: the POZNAN trial. European Heart Journal, 26, 1188-1195.

49. Yokoyama, S., Fukuda, N., Li, Y., Hagikura, K., Takayama, T., Kunimoto, S., et al. (2006). A strategy of retrograde injection of bone marrow mononuclear cells into the myocardium for the treatment of ischemic heart disease. Journal of Molecular and Cellular Cardiology, 40, 24-34.

50. Thompson, C. A., Nasseri, B. A., Makower, J., Houser, S., McGarry, M., Lamson, T., et al. (2003). Percutaneous transvenous cellular cardiomyoplasty. A novel nonsurgical approach for myocardial cell transplantation. Journal of the American College of Cardiology, 41, 1964-1971.

51. Muller-Ehmsen, J., Krausgrill, B., Burst, V., Schenk, K., Neisen, U. C., Fries, J. W., et al. (2006). Effective engraftment but poor mid-term persistence of mononuclear and mesenchymal bone marrow cells in acute and chronic rat myocardial infarction. Journal of Molecular and Cellular Cardiology, 41, 876-884.

52. Li, S. H., Lai, T. Y., Sun, Z., Han, M., Moriyama, E., Wilson, B., et al. (2009). Tracking cardiac engraftment and distribution of implanted bone marrow cells: comparing intra-aortic, intravenous, and intramyocardial delivery. The Journal of Thoracic and Cardiovascular Surgery, 137, 1225-1233.

53. Terrovitis, J., Lautamaki, R., Bonios, M., Fox, J., Engles, J. M., $\mathrm{Yu}$, J., et al. (2009). Noninvasive quantification and optimization of acute cell retention by in vivo positron emission tomography after intramyocardial cardiac-derived stem cell delivery. Journal of the American College of Cardiology, 54, 1619-1626.

54. Freyman, T., Polin, G., Osman, H., Crary, J., Lu, M., Cheng, L., et al. (2006). A quantitative, randomized study evaluating three methods of mesenchymal stem cell delivery following myocardial infarction. European Heart Journal, 27, 1114-1122. 
55. Hou, D., Youssef, E. A., Brinton, T. J., Zhang, P., Rogers, P., Price, E. T., et al. (2005). Radiolabeled cell distribution after intramyocardial, intracoronary, and interstitial retrograde coronary venous delivery: implications for current clinical trials. Circulation, 112, I150-I156.

56. Terrovitis, J. V., Smith, R. R., \& Marban, E. (2010). Assessment and optimization of cell engraftment after transplantation into the heart. Circulation Research, 106, 479-494.

57. Kawamoto, A., Tkebuchava, T., Yamaguchi, J., Nishimura, H., Yoon, Y. S., Milliken, C., et al. (2003). Intramyocardial transplantation of autologous endothelial progenitor cells for therapeutic neovascularization of myocardial ischemia. Circulation, 107, 461-468.

58. Fuchs, S., Baffour, R., Zhou, Y. F., Shou, M., Pierre, A., Tio, F. O., et al. (2001). Transendocardial delivery of autologous bone marrow enhances collateral perfusion and regional function in pigs with chronic experimental myocardial ischemia. Journal of the American College of Cardiology, 37, 1726-1732.

59. Assmus, B., Tonn, T., Seeger, F. H., Yoon, C. H., Leistner, D., Klotsche, J., et al. (2010). Red blood cell contamination of the final cell product impairs the efficacy of autologous bone marrow mononuclear cell therapy. Journal of the American College of Cardiology, 55, 1385-1394.

60. Schneider, C., Jaquet, K., Geidel, S., Rau, T., Malisius, R., Boczor, S., et al. (2009). Transplantation of bone marrow-derived stem cells improves myocardial diastolic function: strain rate imaging in a model of hibernating myocardium. Journal of the American Society of Echocardiography, 22, 1180-1189.

61. Krause, K., Schneider, C., Lange, C., Kokturk, B., Boczor, S., Geidel, S., et al. (2009). Endocardial electrogram analysis after intramyocardial injection of mesenchymal stem cells in the chronic ischemic myocardium. Pacing and Clinical Electrophysiology, 32, 1319-1328.

62. Beeres, S. L., Zeppenfeld, K., Bax, J. J., Dibbets-Schneider, P., Stokkel, M. P., Fibbe, W. E., et al. (2007). Electrophysiological and arrhythmogenic effects of intramyocardial bone marrow cell injection in patients with chronic ischemic heart disease. Heart Rhythm, 4, 257-265.

63. Fuchs, S., Satler, L. F., Kornowski, R., Okubagzi, P., Weisz, G., Baffour, R., et al. (2003). Catheter-based autologous bone marrow myocardial injection in no-option patients with advanced coronary artery disease: a feasibility study. Journal of the American College of Cardiology, 41, 1721-1724.

64. Briguori, C., Reimers, B., Sarais, C., Napodano, M., Pascotto, P., Azzarello, G., et al. (2006). Direct intramyocardial percutaneous delivery of autologous bone marrow in patients with refractory myocardial angina. American Heart Journal, 151, 674-680.

65. Beeres, S. L., Bax, J. J., Roes, S. D., Lamb, H. J., Fibbe, W. E., de, R. A., et al. (2007). Intramyocardial bone marrow cell transplantation and the progression of coronary atherosclerosis in patients with chronic myocardial ischemia. Acute Cardiac Care, 9, 243-251.
66. Losordo, D. W., Schatz, R. A., White, C. J., Udelson, J. E., Veereshwarayya, V., Durgin, M., et al. (2007). Intramyocardial transplantation of autologous CD34+ stem cells for intractable angina: a phase I/IIa double-blind, randomized controlled trial. Circulation, 115, 3165-3172.

67. Meluzin, J., Mayer, J., Groch, L., Janousek, S., Hornacek, I., Hlinomaz, O., et al. (2006). Autologous transplantation of mononuclear bone marrow cells in patients with acute myocardial infarction: the effect of the dose of transplanted cells on myocardial function. American Heart Journal, 152, 975-915.

68. Losordo, D. W., Henry, T. D., Schatz, R. A., et al. (2010). Autologous CD34+ cell therapy for refractory angina: 12 month results of the phase II ACT34-CMI study [abstract]. Circulation, 120, S1123.

69. Willerson, J. T., Perin, E. C., Ellis, S. G., Pepine, C. J., Henry, T. D., Zhao, D. X., et al. (2010). Intramyocardial injection of autologous bone marrow mononuclear cells for patients with chronic ischemic heart disease and left ventricular dysfunction (First Mononuclear Cells injected in the US [FOCUS]): Rationale and design. American Heart Journal, 160, 215-223.

70. Wojakowski, W., Tendera, M., Kucia, M., Zuba-Surma, E., Paczkowska, E., Ciosek, J., et al. (2009). Mobilization of bone marrow-derived Oct-4+ SSEA-4+ very small embryonic-like stem cells in patients with acute myocardial infarction. Journal of the American College of Cardiology, 53, 1-9.

71. Bartunek, J., Vanderheyden, M., Hill, J., \& Terzic, A. (2010). Cells as biologics for cardiac repair in ischaemic heart failure. Heart, 96, 792-800.

72. Gersh, B. J., Simari, R. D., Behfar, A., Terzic, C. M., \& Terzic, A. (2009). Cardiac cell repair therapy: a clinical perspective. Mayo Clinic Proceedings, 84, 876-892.

73. Sorrentino, S. A., Bahlmann, F. H., Besler, C., Muller, M., Schulz, S., Kirchhoff, N., et al. (2007). Oxidant stress impairs in vivo reendothelialization capacity of endothelial progenitor cells from patients with type 2 diabetes mellitus: restoration by the peroxisome proliferator-activated receptor-gamma agonist rosiglitazone. Circulation, 116, 163-173.

74. Behfar, A., Yamada, S., Crespo-Diaz, R., Nesbitt, J. J., Rowe, L. A., Perez-Terzic, C., et al. (2010). Guided cardiopoiesis enhances therapeutic benefit of bone marrow human mesenchymal stem cells in chronic myocardial infarction. Journal of the American College of Cardiology, 56, 721-734.

75. Haider, H. K., \& Ashraf, M. (2010). Preconditioning and stem cell survival. J Cardiovasc Transl Res, 3, 89-102.

76. Webber, M. J., Tongers, J., Renault, M. A., Roncalli, J. G., Losordo, D. W., \& Stupp, S. I. (2010). Development of bioactive peptide amphiphiles for therapeutic cell delivery. Acta Biomaterialia, 6, 3-11.

77. Bartunek, J., Sherman, W., Vanderheyden, M., Fernandez-Aviles, F., Wijns, W., \& Terzic, A. (2009). Delivery of biologics in cardiovascular regenerative medicine. Clinical Pharmacology and Therapeutics, 85, 548-552. 